\title{
Aspectes de la morfologia verbal del català antic en els Sermons de sant Vicent Ferrer
}

\section{Verbal morphology issues of old Catalan in Saint Vincent Ferrer's Sermons ${ }^{1}$}

\author{
Manuel Badal Bertolín \\ Universitat de València \\ manuel.badal@uv.es
}

Data de recepció: 23/03/2018

Data d'aceptació: 02/07/2018

\section{Resum}

En aquest treball d'investigació s'analitzen diversos aspectes de la morfologia verbal històrica del català. Així, a través d'un volum dels Sermons de sant Vicent Ferrer, estudiarem l'estat de llengua que presenten, a principis del segle XV, les marques flexives de primera persona del present d'indicatiu i de les persones del singular del present del subjuntiu. El marc teòric emprat ha estat la Morfologia Natural, la qual tracta d'explicar, a partir de principis generals de caràcter cognitiu i semiòtic, la manera com s'organitzen els paradigmes flexius i els canvis que s'hi solen produir. L'objectiu que ens hem plantejat consisteix a justificar per què l'obra estudiada presenta diferents marques en les formes analitzades (morf zero, $-e$ i $-o$ ) i quin estadi evolutiu mostren. Així mateix, també tractarem de comprovar si aquest estadi s'ha mantingut o ha seguit transformant-se amb el pas dels segles, tenint en compte els trets de cada varietat dialectal que condicionen l'adopció d'una determinada forma.

Paraules clau: flexió verbal; morfologia històrica; canvis analògics; català antic; marques de persona i temps.

\begin{abstract}
In this research paper, we analyse several aspects of the historical verbal morphology of Catalan. Through a volume of the Saint Vincent Ferrer's Sermons, we will study the state of language that present, at the beginning of the 15th century, the first-person marks of indicative present and the singular persons of subjunctive present. The theoretical framework used has been Natural Morphology, which tries to explain, based on general principles of a cognitive and semiotic nature, the way in which phrasal paradigms are organised and the changes that are usually produced. The objective we have set is to justify why this work presents different marks in the analysed forms (zero morph, $-e$ and $-o$ ) and which evolutionary stage they show. In addition, we will see whether this stage has been maintained or has continued to be transformed over the centuries, considering the features of each dialectal variety that condition the adoption of a certain form.
\end{abstract}

Keywords: verbal inflection; historical morphology; analogue changes; old Catalan; person and time marks.

\footnotetext{
1 Aquest estudi ha estat finançat pel programa de subvencions per a la contractació de personal investigador de caràcter predoctoral (ACIF/2017) de la Generalitat Valenciana, i forma part dels projectes d'investigació “Continuación de la Gramática del Catalán Moderno (1600-1833)" (FFI2015-69694-P - MINECO/FEDER) de la Universitat d'Alacant i "Fenómenos de interfaz fonética-fonología-morfología desde la perspectiva de la variación lingüística” (FFI2016-76245-C3-3-P) de la Universitat de Barcelona.
} 



\section{Taula de continguts}

1. Introducció

1.1. Els principis de naturalitat independents del sistema

1.2. Els principis de naturalitat dependents del sistema

2. La primera persona del present d'indicatiu en els Sermons

3. Les persones rizotòniques del singular del present de subjuntiu

4. Conclusions

Bibliografia 



\section{Introducció}

La llengua catalana, descendent de la llatina, s'agrupa amb les llengües romàniques occidentals, com el francès, l'occità o el castellà. Al seu torn, aquestes llengües es poden subagrupar en famílies. En l'actualitat s'assumeix majoritàriament que el català és inicialment una llengua gal·loromànica, si bé és cert que a partir del s. XV inicia un decantament cap a les llengües iberoromàniques. Un dels comportaments que situen clarament el català dins la Gal·loromània té a veure amb un canvi fonològic que tindrà importants repercussions en l'evolució de la flexió verbal, com veurem al llarg de l'article. Ens referim a la caiguda d'àtones finals diferents de $a$, que provocà, per exemple, que la primera persona del present d'indicatiu quedara reduïda al radical, com mostren les formes am, del català i l'occità antic. Aquest canvi fonològic provocà posteriorment altres canvis ara de caràcter morfològic, com mostra l'adopció de desinències vocàliques com a marques de primera persona del present d'indicatiu: inicialment $-e$ i, posteriorment altres en alguns casos: ame (català antic i valencià general actual), amo (català general), ami (occità, rossellonès i Cadaqués).

Aquests canvis morfològics tenen un origen analògic. L'analogia és un procediment de canvi que pot afectar diferents nivells de la gramàtica, però és especialment productiu en l'àmbit de la morfologia flexiva. L'analogia consisteix en una sobregeneralització, o en una generalització abusiva, atès que parteix de formes ja existents en la llengua i les generalitza

a contextos en què no existien inicialment. És el mecanisme de canvi lingüístic que té major importància a l'hora de justificar els canvis que s'analitzaran en aquest treball, ja que és el canvi morfològic per naturalesa.

L'estudi de la morfologia verbal en els Sermons de sant Vicent Ferrer és interessant perquè el text té trets fonètics, lèxics i morfològics del català occidental, alguns atribuïbles als reportadors, com ara els subjuntius en $o$, desconeguts a la zona central del regne de València, però freqüents a les comarques septentrionals i al pla de Lleida (Ferrando i Nicolàs, 2012: 117). A més, el fet que es tracte d'un text de caràcter oral, possibilita que apareguen formes que en textos d'una formalitat més elevada serien difícils de trobar. Em referisc, per exemple, a les 
esmentades formes del subjuntiu, que s'han mantingut col·loquialment en una part del català nord-occidental fins a l'actualitat (p. ex. que tu cantos), però que difícilment es documenten en els textos, segurament pel fet que se sentien com a col·loquials i es bandejaven de l'escriptura. Així, malgrat que el treball de corpus és imprescindible per a fer recerca històrica, cal tenir en compte que podem ensopegar amb problemes d'aquesta índole: formes que, malgrat llur antiguitat i extensió diatòpica, són difícils de documentar.

Com s'ha apuntat, la variació flexiva que mostren els Sermons està relacionada amb els canvis analògics. Per a Jerzy Kuryłowicz (1945), perquè es produïsca un canvi analògic cal que els termes que hi participen mantinguen alguna mena de relació gramatical i que la relació s'establisca entre unes formes bàsiques i d'altres de derivades. En un dels casos que analitzarem en aquest treball, en l'analogia participen formes de primera i tercera persona del present d'indicatiu, i les de tercera persona són formes bàsiques respecte a les de primera. Fins i tot, l'analogia es pot establir entre categories gramaticals i no únicament entre mots. Devem a Wheeler la primera gran aportació teòrica en català sobre el concepte de l'analogia. Segons aquest autor (2007: 58), els canvis analògics es justifiquen per la necessitat d'alleujar algun dels problemes psicològics o psicolingüístics que els paradigmes flexius plantegen al parlant de l'idioma com a emissor, receptor o aprenent de la llengua.

En una línia pròxima a la de Wheeler, però amb un model més inclusiu es poden situar les aportacions realitzades des del model de la Morfologia Natural, elaborat per autors que provenien de la fonologia generativa clàssica, especialment per Wolfgang U. Dressler (1985) i pels seus deixebles Willi Mayerthaler (1987) i Wolfgang E. Wurzel (1989). En català ha estat adoptat, entre d'altres, pel mateix Max W. Wheeler (2007), i per Pérez Saldanya (1998).

La Morfologia Natural té com a objectiu explicar les tendències universals en l'estructuració interna dels mots, els processos de formació d'aquests i els canvis analògics que experimenten a partir de principis cognitius generals, anomenats principis de naturalitat. El pressupòsit bàsic es fonamenta en la idea que els paradigmes tendeixen a evitar situacions marcades i a optimitzar-ne l'estructura. Els principis d'optimització morfològica es classifiquen en dos grans blocs. El primer, es refereix a tendències independents dels sistemes lingüístics (veg. 
$\S$ 1.1.). El segon bloc, que és una de les grans aportacions d'aquest model teòric, fa referència a tendències dependents de cada sistema lingüístic (veg. § 1.2.).

\subsection{Els principis de naturalitat independents del sistema}

Dins d'aquests principis, cal diferenciar entre els que remeten a l'anomenat universal de Humboldt $i$ els que remeten al marcatge de les categories morfosintàctiques. Els relacionats amb l'universal de Humboldt fan referència a la tendència general a establir una relació biunívoca entre la forma i la funció de les unitats lingüístiques, i es concreten en el principi de transparència i en el d'uniformitat. Per la seua banda, els que remeten al marcatge de les categories tenen a veure amb el principi d'iconicitat i el principi d'acceptabilitat del sincretisme.

a) El principi de transparència afavoreix els paradigmes sense ambigüitats ni fusions.

b) El principi d'uniformitat afavoreix els paradigmes sense variants al·lomòrfiques.

c) El principi d'iconicitat està relacionat amb les diferències de marcatge funcional existents entre les categories morfosintàctiques i amb la tendència, molt general, que aquestes diferències de marcatge funcional esdevinguen diferències de marcatge formal.

d) L'últim principi independent, relacionat amb el marcatge, té a veure amb l'acceptabilitat del sincretisme en certs contextos. Una mirada ràpida als paradigmes flexius que presenten una certa complexitat permet comprovar fàcilment que hi ha contextos en què el sincretisme s’accepta amb més facilitat que en altres.

\subsection{Els principis de naturalitat dependents del sistema}

Wurzel elabora el concepte de Naturalitat Dependent del Sistema, o naturalitat interna d'una llengua, per tal d'explicar l'evolució dels sistemes flexionals. Com apunta Wheeler (2007: 145-146): «Wurzel raona que els usuaris d’una llengua són sensibles a les característiques predominants de la seva organització estructural, i que tendiran a actuar de manera que aquestes 
característiques es mantinguin o es reforcin». Segons Wurzel, en morfologia la Naturalitat Dependent del Sistema té dues vessants: la congruència amb el sistema i l'estabilitat de les classes flexionals (Wheeler, 2007: 146): «Els elements morfològics d'un sistema o subsistema es tenen com congrus amb el sistema en la mesura que estan conformes amb les característiques definidores de l'estructura del sistema o del subsistema».

Els principis dependents del sistema connecten metodològicament amb el concepte de morfoma, encunyat per Aronoff (1994), i amb l'anomenada Morfologia Autònoma desenvolupada per Maiden et al. (2011) en els seus estudis del verb romànic, i per Wheeler (2007) i Pérez Saldanya (2013) en treballs recents sobre la morfologia verbal del català. Amb el terme morfoma es vol fer referència a alternances formals que presenten una certa recurrència i regularitat dins els paradigmes flexius i que no estan condicionades per la fonologia (no depenen del context fònic) ni per la semàntica o la funció gramatical (no s'associen a cap significat ni a cap funció determinada).

Els principis dependents es troben relacionats amb les propietats gramaticals o formals característiques de cada sistema lingüístic. Aquests principis tenen a veure amb la congruència del sistema lingüístic i amb l'estabilitat de les classes flexives.

a) El principi de congruència del sistema afavoreix els paradigmes organitzats d'una manera uniforme i sistemàtica d'acord amb els paràmetres morfològics de la llengua.

b) El principi d'estabilitat de les classes flexives afavoreix les classes flexives motivades independentment i els paradigmes organitzats a partir de sistemes implicatius generals.

Cal tenir en compte que els diferents principis de naturalitat poden entrar en conflicte, puix que un determinat canvi pot optimitzar un aspecte de l'organització dels paradigmes flexius però pot provocar un resultat no desitjable pel que fa a un altre aspecte. 


\section{La primera persona del present d'indicatiu en els Sermons}

L'expressió morfològica de la primera persona del present d'indicatiu és un dels temes més estudiats de la morfologia històrica catalana, atés que hi ha una important variació dialectal (Blasco Ferrer, 1985; Casanova, 1989; Alsina, 1990; Pérez Saldanya, 1998; Wheeler, 2007). Així, els diferents parlars del català ens il·lustren cadascun dels estadis pels quals ha passat la primera persona del present d'indicatiu de la primera conjugació: en balear i alguerés trobem la desinència zero, originària de tot el català $(p e n s, a m)$; en valencià, la desinència - $e$, que també és originària en els verbs de la primera conjugació que presentaven una vocal de suport (capte, parle) i que tendí a generalitzar-se al llarg del segle XV; el català central i el nord-occidental presenten la desinència $-o$, fruit d'un estadi evolutiu posterior, com ho és també la desinència $-i$ del rossellonés. Fins i tot, trobem la desinència -a (parla, escolta) a Tàrbena, l'Alcora, Costur i les Useres (Beltran i Segura-Llopes, 2018).

Aquesta variació històrica i diatòpica cal relacionar-la amb la necessitat d'optimitzar el paradigma flexiu i amb els conflictes de naturalitat existents entre les diverses tendències d'optimització morfològica i fonològica. La pèrdua de les vocals àtones finals diferents de $-a$ introduí una optimització de caràcter fonològic, ja que s'eliminaren uns sons que devien tenir una articulació molt relaxada i que, consegüentment, no eren fàcils de percebre. No obstant això, provocà uns clars problemes de naturalitat morfològica, de manera que allò que es guanyà en l'àmbit perceptiu i articulatori es perdé en l'àmbit de la sistematicitat i la transparència dels paradigmes flexius. Analitzem, tot seguit, els diferents problemes de naturalitat morfològica que presenten les formes etimològiques de la primera persona del present d'indicatiu dels verbs de la primera conjugació.

a) El problema més evident del paradigma medieval està relacionat amb el principi de transparència, a causa de l'opacitat existent entre la primera persona del present d'indicatiu i la primera i la tercera del present de subjuntiu, totes tres sense marca flexiva (1): 
1) a. 1a per. pres. ind.: CANTŌ $>$ cant

b. 1a per. pres. subj.: CANTEM $>$ cante $>$ cant

c. 3 a per. pres. subj.: CANTET $>$ cante $>$ cant

b) Relacionat amb el punt anterior, el paradigma etimològic resulta problemàtic respecte al principi d'iconocitat. Notem que la primera persona és marcada respecte a la tercera, però a causa de la caiguda d'àtones finals la forma d'aquestes persones no reprodueix la diferència de marcatge. Això és, la primera, tot i ser més marcada que la tercera, no té cap marca (cant) i presenta menys cos fònic que la tercera (canta).

c) Una altra anomalia relacionada també amb les dues anteriors té a veure amb les irregularitats que els paradigmes verbals mostren respecte al nombre de síl·labes de les diferents persones i, sobretot, de les tres primeres persones. Segons Wheeler (2007: 147), això contravé el principi de congruència del sistema proposat per Mayerthaler i Wurzel. Així doncs, la primera persona del present d'indicatiu presentava una única síllaba, enfront de les dues que tenien la resta de formes del present (Blasco Ferrer, 1985: 48-49), com mostra el paradigma de (2).

2) Present d'indicatiu etimològic de cantar

CANTŌ $>$ cant

CANTĀS $>$ cantes

CANTAT $>$ canta/-e

CANTĀMUS $>$ cantam

CANTĀTIS $>$ cantats

CANTĀNT $>$ canten

A més, Casanova (1989: 344-345) afig que la primera persona tenia el mateix nombre de síl·labes que la tercera en la resta de temps i modes verbals de la primera conjugació, però també en els presents dels verbs de les altres conjugacions, la qual cosa feia augmentar més encara aqueixa irregularitat.

d) La darrera anomalia és més aparent que real, i té a veure amb l'existència d'una sèrie de formes de primera persona acabades en la vocal $-e^{2}$ :

2 La forma de primera persona del present d'indicatiu dels verbs de la primera conjugació prenia una -e de suport per tal d'evitar les dificultats articulatòries que implicaria l'existència d'una coda final de mot formada per dues oclusives (capte), oclusiva o fricativa més líquida (compre, infle), dues líquides (parle), vibrant (erre) o 
[...] quan el radical verbal acabava en un grup consonàntic complex, les formes de la 1a. p. s. P. I. Acabaven fonèticament en [e]; altrament, aquesta vocal no apareixia: per exemple, lliure, cobre, etc., al costat de port, am, etc. [...] Això requeria la postulació d'una regla d'epèntesi vocàlica que afegia la vocal [e] als radicals acabats en certs aplecs consonàntics, com per exemple els formats per dues oclusives o per una consonant i una líquida. [...] unes quantes formes de la I conjugació en què el radical no va seguit ni d'una [a] o [e] àtones ni d'una [á] tònica: es tracta precisament de la 1a. p. s. P. I. i de tot el present de subjuntiu (excepte a 3a. p. pl.). (Alsina, 1990: 90-92)

L'existència en el català més antic de formes de primera persona reduïdes al radical (am) i de formes acabades en -e (compre) estava, doncs, condicionada fonològicament. Tot i amb això, aquesta - $e$ fàcilment podia associar-se a una marca flexiva, i la seua generalització a totes les formes de primera persona del present d'indicatiu dels verbs de la primera conjugació permetia resoldre part dels problemes de naturalitat morfològica, com ara la manca de congruència sil·làbica existent entre la primera i la tercera persona del present d'indicatiu dels verbs de la primera conjugació:

[...] l'anivellament morfològic entre 1. ${ }^{\mathrm{a}} \mathrm{i} 3 .^{\mathrm{a}}$ persona és general i regular en tots els restants temps verbals de la $1 .^{\text {a }}$ conjugació, per la qual cosa tot el sistema espentava a l'anivellament sil làbic. Precisament els únics casos d'anivellament sil·làbic i simetria amb les altres conjugacions es donava en els verbs acabats en els grups consonàntics dalt esmentats, gràcies a la vocal de suport $-e[\ldots]$ els quals abundaven en la 1 . $^{\mathrm{a}}$ conjugació. (Casanova, 1989: 345)

A més, corregia l'anomalia que implicava que la primera persona, forma marcada respecte a la tercera, tinguera menys marca formal que no aquesta. Açò es relaciona amb el principi d'iconicitat. Cal tenir en compte que les categories no marcades es diferencien de les marcades perquè tenen un significat més bàsic, perquè presenten una major freqüència d'ús, perquè tenen un caràcter extensiu i perquè s'assoleixen abans en el procés d'aprenentatge lingüístic. A més, formalment, les formes no marcades presenten sovint la desinència zero, enfront de les marcades, que solen tenir desinències fonèticament realitzades i són més regulars.

semivocal més líquida (lliure). 
D'acord amb això, els parlants tendiren a morfologitzar la -e de suport i a interpretar-la com a marca de primera persona del present d'indicatiu en els verbs de la primera conjugació, i començaren a estendre-la a la resta de verbs que no la necessitaven. Aquest fenomen, propi de totes les llengües gal·loromàniques (francés, occità i català), començà al segle XI i s'estengué fins a imposar-se totalment al segle XVI en el català general.

En els Sermons trobem, com és esperable pel moment en què foren predicats i compilats, tant formes sense cap marca flexiva (3a), com formes amb la marca $-e(3 b)$ :

3) a. Yo trop que són tres maneres de aconseguir lo regne celestial, e són aquestes (p. 8)

b. Per ço de la fi del món que yo preÿque ara, dirie algú (p. 151)

A més de les formes sense marca o amb la marca -e, també trobem casos de formes amb la marca $-o(4)$ :

4) Jordi, no saps tu que aquells que confessen la fe cristiana, que yo los mato? (p. 80)

Indiquem tot seguit, el recompte de formes verbals de primera persona del present d'indicatiu dels verbs de la primera conjugació. En la taula s'ha inclòs la forma parle, en què la -e és etimològica ja que actua com a vocal de suport.

\begin{tabular}{lll}
$\varnothing$ & $-\mathrm{e}$ & $-\mathrm{o}$ \\
\hline $\begin{array}{l}\text { ador x2, certifich, deman, } \\
\text { gós, man x3, pens x8, perdó, } \\
\text { prech x11, trop x } 8\end{array}$ & & \\
& & \\
verbs 9 & verbs 6 & verbs 2 \\
formes $36(80 \%)$ & formes 7 & formes $2(4,4 \%)$ \\
& $(15,6 \%)$ & \\
\hline
\end{tabular}

Taula 1. Formes de primera persona del present d'indicatiu

Com podem observar en la taula 1, són encara majoritàries les formes etimològiques sense cap marca flexiva. Les formes amb la marca - $e$ comencen a introduir-se, però encara molt tímidament. Aquestes dades corroboren la constatació que fa Wheeler (2012: 876) en el seu estudi sobre la morfologia verbal del Curial e Güelfa, en el sentit que la generalització de la -e no és massa freqüent fins a la segona meitat del segle XV. D’aquesta manera, els Sermons, 
predicats cap a la primeria del segle $\mathrm{XV}$ i, segurament, transcrits a meitat segle $\mathrm{XV}$, responen a l'estadi evolutiu adés esmentat, en què les formes innovadores en - $e$ ja apareixen, però encara són minoritàries.

Cal fer esment de l'aparició de la desinència -o, la més innovadora de la primera persona del present d'indicatiu i la que acabarà triomfant tant en el català nord-occidental (incloent-hi el valencià septentrional) com en el català central. L'aparició d'aquesta marca es deu al fet que en nord-occidental la desinència - $e$ de primera persona presentava problemes, ja que en aquest dialecte la desinència llatina de tercera persona -at havia evolucionat a -e, segurament a partir dels canvis exemplificats en $(5)^{3}$.

5) CANTAT $>$ cantet $>$ cante

D'acord amb això, no és estrany que la -e s'haja mantingut estable fins a l'actualitat en valencià, en què canta es pronuncia cant [a], però no en els altres parlars en què com el nordoccidental, l'adopció de la -e en la primera persona provocava un sincretisme amb la tercera persona ( 1 cant $[\mathrm{e}]$ vs. $3 \operatorname{cant}[\mathrm{e}])$. L'origen d'aquesta desinència ha estat estudiat per Coromines (1983) i Gulsoy (1993). L’aparició de la -o, doncs, es deuria:

[...] a un procés d'assimilació que canvia el timbre de la /e/ final convertint-la en /o/ quan el radical presentava una $o$ o $u$ tònica. Aquesta vocal, d'altra banda, acabaria morfologitzant-se i generalitzant-se en la primera conjugació per tal com permetia resoldre problemes d'homofonia. (Pérez Saldanya, 1998: 167)

Als Sermons, però, aquesta solució és encara molt escassa, ja que com veiem només presenta dos casos. Pel que fa a la freqüència d'ús, en aquest cas promou el manteniment de les formes amb sufix zero, ja que les tres formes verbals de primera persona que més apareixen, no presenten cap desinència. Cal tenir en compte que l'aparició de la o no requereix que s'haja generalitzat la $-e$, com en principi es podria creure. D'una banda, el sincretisme ja es produïa amb les formes amb -e de suport (jo parl[e] vs. ell(a) parl[e]). D'una altra, el problema s'agreuja

3 He adoptat el punt de vista segons el qual la $t$ és més persistent en català occidental i es manté com a mínim fins al moment en què ja s'ha produït en el català general el canvi de $a$ àtona final en $e$ en síl·laba travada (e.g. DOMINAS > donas $>$ dones). També és possible, però que el canvi fos analògic i que la tercera persona canviara la $a$ per la $e$ per analogia a les altres persones amb desinència vocàlica i accent en el radical: la segona (cantes) $\mathrm{i}$ la sisena (canten). Per a una explicació basada en el canvi fonològic, veg. Wheeler (2007) i per a una explicació basada en el canvi analògic, Massanell (2016). 
en la mesura que afecta més formes verbals, en el moment en què comença a generalitzar-se la $-e$ de suport.

\section{Les persones rizotòniques del singular del present de subjuntiu}

Històricament, les formes rizotòniques del present de subjuntiu han tingut una evolució diferent de les formes arizotòniques. Si, en el primer cas, s'han produït una sèrie de canvis que justifiquen la diversitat diatòpica i la tendència, en part, a diferenciar el subjuntiu de l'indicatiu, en el segon, s'han produït canvis que han provocat la igualació de tots dos modes en la major part de l'àmbit lingüístic (per exemple cantem i canteu com a formes de quarta i cinquena persones del present d'indicatiu i de subjuntiu).

En el català actual, en les formes rizotòniques del present de subjuntiu trobem un grau de variació semblant al de la primera persona del present d'indicatiu. Les causes d'aquesta variació són semblants a les que ja s'han analitzat per a aqueixa persona. Aquesta variació està relacionada amb els problemes de naturalitat morfològica provocats per l'evolució fonètica regular del llatí tardà (o el català primitiu) i pels processos de canvi morfològic introduïts per a atorgar una major naturalitat a la conjugació del present de subjuntiu.

Com ja s'ha comentat més amunt, la regla fonològica històrica de la caiguda de vocals àtones finals havia deixat les formes del singular del present de subjuntiu de la primera conjugació sense cap marca de mode (6).

6) 1a pers. pres. subj.: CANTEM $>$ cant

2a pers. pres. subj.: CANTĒS $>$ cants

3a pers. pres. subj.: CANTET $>$ cant

La caiguda d'àtones finals, doncs, havia provocat que la primera persona del present d'indicatiu i les tres primeres persones del present de subjuntiu perderen la desinència vocàlica. Açò només ocorregué en la primera conjugació, ja que en les altres dues aquesta caiguda només havia afectat les formes d'indicatiu, atés que les formes de subjuntiu tenien com a marca flexiva la vocal $-a$, que no es véu sotmesa a la caiguda d'àtones finals (per exemple, DICAM $>$ diga, 
DORMIAM > dorma). D’aquesta manera, les anomalies dels paradigmes medievals de subjuntiu són paral·leles a les que s'han comentat més amunt per a la primera persona del present d'indicatiu (veg. § 2): l'opacitat, el desnivellament sil·làbic, la contraiconicitat i la manca d'uniformitat. I les solucions que s'adoptaren són, en part, paral·leles a les introduïdes en la primera persona del present d'indicatiu dels verbs de la primera conjugació.

a) Tal com han assenyalat Coromines (1983), Gulsoy (1993) i, especialment, Pérez Saldanya (1998), un dels problemes del paradigma medieval està relacionat amb l'opacitat, que es manifesta en la primera persona del present d'indicatiu i en la primera i la tercera del present de subjuntiu dels verbs de la primera conjugació (totes sense marca flexiva).

b) Una altra anomalia important del sistema flexiu és la que es refereix a les regularitats que els paradigmes verbals mostren respecte al nombre de síl·labes i a la presència $\mathrm{o}$ absència de desinències sil·làbiques. La segona i tercera conjugació eren regulars pel que fa a les desinències vocàliques i al nombre de síl·labes de totes les persones, totes amb dues síl·labes. En la primera conjugació, en canvi, no hi havia homogeneïtat, ja que les tres primeres persones freturaven de desinència vocàlica $i$, en conseqüència, tenien una síl·laba menys que les persones del plural.

c) Com ja s'ha esmentat en el capítol anterior, l'anomalia més important té a veure amb el principi d'iconicitat, ja que des d'un punt de vista semàntic i funcional, el subjuntiu és un mode marcat per oposició a l'indicatiu. En els verbs de la primera conjugació ocorria el següent:

En la primera persona, l'oposició no era icònica i es produïa un sincretisme entre els dos modes; en les altres dues persones del singular, d'altra banda, l'oposició era contraicònica, puix que les formes no marcades d'indicatiu tenien una marca vocàlica, enfront de les marcades de subjuntiu, que no en tenien cap. (Pérez Saldanya, 1998: 152)

d) Com succeeix amb la primera persona dels verbs de la primera conjugació, les formes del singular del present de subjuntiu d'aquests mateixos verbs també presentaven una -e de suport en aquells casos en què es produïen dificultats articulatòries en certes codes, com hem vist anteriorment (veg. $§$ 2.1.). 
A banda de la vocal de suport que apareixia en els casos adés esmentats, en què les codes presentaven dificultats perceptives o articulatòries, cal afegir un altre cas més relacionat amb la segona persona. Es tracta dels verbs amb un radical que acaba en consonant sibilant. En aquests casos, la vocal epentètica permetia diferenciar la consonant final del radical i la desinència de segona persona $-s \mathrm{i}$, consegüentment, atorgar una estructura sil·làbica al conjunt: que tu cases. Com a resultat, les persones del singular del present de subjuntiu dels verbs de la primera conjugació presentaven una variació en el present de subjuntiu, ja que juntament amb les formes que no posseïen cap vocal final, n'hi havia d'altres que sí que en presentaven.

El nombre de casos trobats de les tres primeres persones del subjuntiu difereix molt. En primer lloc, pel que fa a la primera persona, només trobem un cas, que presenta la desinència - $e$ (7), la qual cosa no ens permet extraure conclusions i només ens serveix per a confirmar que la marca - e ja s'havia introduït en el present de subjuntiu:

7) Si·1 meu adversari se evite de anar a Antecrist, ell obtendrà: més val que yo m’í cuyte. (p. 233)

Quant a la segona persona, hi trobem pocs casos. La forma majoritària de casos no presenten cap marca (8a), encara que també trobem alguns casos de formes acabades en -es (8b) i -os (8c).

8) a. e puix dix fins a "in manus tuas", per donar-te exemple que sies diligent en fer oració e servir Déu e que $t$ guards de perea. (p. 67) b. bona demanda és a Déu que li demanes que tu, moro o juheu, demanes que t'il·lumene en la fe (p. 8)

c. Axí tu, ans que muntos en lo llit per malaltia, te deus despullar, restituint los torts (p. 66)

La persona que ens permet d'analitzar d'una manera més àmplia l'estadi evolutiu de les formes de subjuntiu és la tercera (taula 2), ja que trobem molts més casos que en les altres dues persones. Les dues formes majoritàries, és a dir, les que no presenten cap marca (9a) i les que incorporen la marca $-e(9 \mathrm{~b})$, presenten pràcticament el mateix nombre de casos. La presència 
de les formes amb -o (9c) és bastant inferior als dos casos anteriors, la qual cosa ens fa pensar que és un fenomen recent que encara no s'ha estés gaire o bé que és un fenomen que es tendia a evitar en l'escriptura.

9 a. Mas lo perill és a les males persones, que no y ha qui les aconsol sinó lo dimoni que les acuse, etc. (p. 37)

b. Mas veus ací lo remey que la creatura pot haver: que s'humilie per oració, e la carn per abstinència, segons dix Jesuchrist (p. 40)

c. Sent Johan per sciència conech a Jesuchrist, mas sent Pere per amor hi fo primer, e axí, qui vol haver sciència, conservo $\cdot$ s pur (p. 13)

\begin{tabular}{|c|c|c|}
\hline$\varnothing$ & $-e$ & -0 \\
\hline $\begin{array}{l}\text { acap, aconsol, ajud, deman, dó x2, } \\
\text { dón x3, gós x2, govern, guard x3, } \\
\text { man x2, perdó, tir }\end{array}$ & $\begin{array}{l}\text { concorde } x 2 \text {, demane } x 2 \text {, fique, hu- } \\
\text { milie, il·lumene, incline, lexe, nome- } \\
\text { ne, porte, preserve, refrene } x 2 \text {, serve, } \\
\text { tire, torne }\end{array}$ & conservo x2, dexo, passo, salvo \\
\hline $\begin{array}{l}\text { verbs } 12 \\
\text { formes } 19(46,34 \%)\end{array}$ & $\begin{array}{l}\text { verbs } 14 \\
\text { formes } 17(41,46 \%)\end{array}$ & $\begin{array}{l}\text { verbs } 4 \\
\text { formes } 5(12,2 \%)\end{array}$ \\
\hline
\end{tabular}

Taula 2. Formes de tercera persona del present de subjuntiu

A primera vista pot semblar que tant les formes no marcades com les que presenten marca flexiva es troben igualment esteses. Tanmateix, si ens fixem en la diversitat de verbs en què apareixen, les formes en - $e$ es troben en un procés d'expansió, ja que apareixen en un nombre més elevat de verbs diferents. Aquest canvi es relaciona amb el principi d'iconicitat adés esmentat, ja que el subjuntiu és un temps marcat respecte de l'indicatiu i, per tant, és lògic que adquirisca una marca flexiva que l'identifique.

A més de les persones del singular, cal fer referència també a la sisena persona (o la tercera del plural). Com ja s'ha indicat, la sisena persona exigeix una vocal de suport, però és important de remarcar que juntament amb les formes acabades en -en, hi ha dos casos de formes en -on (10), que permeten constatar també l'extensió que estava assolint aquesta marca en el subjuntiu. 


\section{Conclusions}

Com s'ha esmentat en la introducció, els Sermons de sant Vicent Ferrer és bastant interesant per a l'estudi de la primera persona del present d'indicatiu de la primera conjugació i de les persones rizotòniques del singular del present de subjuntiu de la primera conjugació, ja que mostra trets del valencià, però també del nord-occidental, a causa de la filiació del copista. A més, el fet que el text siga de caràcter oral possibilita l'aparició de marques verbals que en un text d'una formalitat més elevada serien difícils de trobar, com ara la marca o de subjuntiu. El nombre de casos documentats ens ha permés fer una anàlisi bastant fonamentada, sobretot quant a la primera persona del present d'indicatiu i la tercera del present de subjuntiu.

Pel que fa a la primera persona del present d'indicatiu, en el parlar en què estan recollits els Sermons la morfologització de la -e de suport en la primera persona provocava un sincretisme amb la tercera persona del present d'indicatiu també acabada en -e, com també ocorria en el central, però en aquest darrer per una raó diferent: la reducció de les vocals àtones /a/ i /e/ en la vocal neutra [ə]. Així, l'únic parlar en què la generalització de la -e com a marca de la primera persona del present d'indicatiu podria triomfar era en el valencià general, ja que en aquesta varietat no es produïa el sincretisme entre la primera persona (cante) i la tercera (canta).

En els Sermons, la presència de formes amb l'afix -e és anecdòtica enfront de les formes de primera persona no marcades, ja que aquestes evitaven el sincretisme a què acabem de fer referència. La desinència de la primera persona, doncs, no era estable, i la tercera persona presentava dues desinències, en - $e$ i en $-a$, malgrat que la primera era la majoritària, la qual cosa provocava l'esmentat sincretisme. Fins i tot, aparegué una nova terminació en - $o$, la qual és present als Sermons, per tal de desfer el sincretisme. Cal esmentar, però, que la forma que gaudia de més prestigi en la tercera persona era la minoritària en aqueix moment, és a dir, la $-a$, que acabà imposant-se a la diòcesi de València. Consegüentment, eliminat en aquesta àrea 
el sincretisme entre la primera i tercera persona del present d'indicatiu, la vocal -e s'estengué ràpidament $\mathrm{i}$ acabà triomfant com a desinència de la primera persona al final del segle XV.

Quant a les formes rizotòniques del singular del present de subjuntiu en els verbs de la primera conjugació, després d'haver realitzat el recompte de formes, hem pogut comprovar que la generalització analògica de la -e i la seua reanàlisi com a marca de present de subjuntiu està més avançada en la tercera persona que en la segona. Una de les explicacions més factibles és que la necessitat de dotar de marca el subjuntiu és més important en la tercera que no pas en la segona. D'acord amb això, podem plantejar la hipòtesi que el factor més important no és fonològic sinó morfològic; concretament, la necessitat més forta de dotar de marca específica de mode la persona més freqüent i la menys marcada.

Malgrat tot, la morfologització mantenia el sincretisme entre indicatiu i subjuntiu en la primera persona i, a més, introduïa un de nou en la segona persona i, en la majoria de dialectes, també en la tercera. En aquesta darrera persona no hi havia sincretisme en valencià general, que presentava una - $a$ en indicatiu i una - $e$ en subjuntiu, però sí en nord-occidental i en oriental. Llavors, l'únic dialecte en el qual la tercera persona es diferenciava en els dos modes era el valencià general. Aquesta solució, doncs, no podia ser definitiva en tots els dialectes catalans, per la qual cosa s'han produït innovacions morfològiques posteriors. La marca - $o$ és la més antiga de les innovacions morfològiques del subjuntiu en català, després de la generalització de la -e. Encara que les formes de subjuntiu en - $o$ són tan antigues com les formes de primera persona del present d'indicatiu en $-o$, probablement no deixà mai de sentir-se com una forma col $\cdot$ loquial, poc apta per a l'escriptura. 


\section{Bibliografia}

Alsina, À. (1990). «Un aspecte de la morfologia històrica catalana. La primera persona del singular del present d'indicatiu», en Llengua \& literatura, Volum 3, pp. 89-119.

Aronoff, M. (1994). Morphology by itself: stems and inflectional classes. Cambridge: MIT Press.

Beltran, V. i Segura-Llopes, C. (2018). Els parlars valencians. València: PUV.

Blasco Ferrer, E. (1985). «Les desinències de la primera persona del present d'indicatiu en català i en occità. Estudi diacrònic de morfosintaxi gal·loromànica», en Estudis de llengua $i$ literatura catalanes, Volum 10, pp. 37-87.

Casanova, E. (1989). «Gramàtica històrica i història de la llengua. A propòsit de l'evolució de la desinència de la persona del present d'indicatiu», en Actes del Segon Congrés Internacional de la Llengua Catalana, pp. 343-357.

Coromines, J. (1983). Lleures i converses d'un filòleg. Barcelona: Club Editor.

Dressler, W. U. (1985). «Morphologization of Phonological Processes (Are there distinct morphonological processes)?», en Juilland, A. (Ed.) Linguistic Studies Offered to Joseph Greenberg, pp. 317-337. Saratoga: Anima Libri.

Ferrando, A. i Nicolàs, M. (2012). Història de la llengua catalana. Barcelona: UOC.

Gulsoy, J. (1993). Estudis de gramàtica històrica. València/Barcelona: IIFV/PAM.

Kuryłowicz, J. (1945). «La nature des procès dits "analògiques”». Acta lingüística, Volum 5, pp. 15-37.

Maiden, M.; Smith, J. C.; Goldbach, M. i Hinzelin, M. O. (2011). Morphological Autonomy. Perspectives from Romance Inflectional Morphology. Oxford: Oxford University Press.

Massanell, M. (2016). «Sincretisme i canvi morfològic: evolució de la terminació verbal en -at en català», en Caplletra, Volum 61, pp. 165-209. 
Mayerthaler, W. (1987). «System-independent morphological naturalness», en Dressler, Wolfgang U.; Mayerthaler, Willi; Panagl, Oswald i Wolfgang U. Wurzel (Ed.) Leitmotifs in natural morphology, pp. 25-58. Amsterdam/Filadèlfia: John Benjamins.

Pérez Saldanya, M. (1998). Del llatí al català. Morfosintaxi verbal històrica. València: PUV.

Pérez Saldanya, M. (2013). «"Que sa il·lustre senyoria cullga o faça cullir dits fruits”: una aproximació històrica als verbs velaritzats», en Qüestions de morfologia flexiva i lèxica del català. Volum d'homenatge a Joaquim Viaplana, Volum 24, pp. 313-334.

Wheeler, M. W. (2007). Morfologia i fonologia catalana i romànica: estudis diacrònics. Alacant/ Barcelona: IIFV/PAM.

Wheeler, M. W. (2012). «La morfologia verbal al Curial e Güelfa», en Ferrando, Antoni (Ed.) Estudis lingüístics i culturals sobre Curial e Güelfa: Novel·la cavalleresca anònima del segle XV en llengua catalana, pp. 875-908. Amsterdam: John Benjamins.

Wurzel, W. U. (1989). Inflectional Morphology and Naturalness: Dordrecht/Boston/Londres: Kluwer Academic Publishers. 